\title{
Feasibility of spectral shaping for detection and quantification of coronary calcifications in ultra-low dose CT
}

\author{
Marleen Vonder $^{1,2}$ • Gert Jan Pelgrim ${ }^{1,2} \cdot$ Sèvrin E. M. Huijsse ${ }^{1} \cdot$ Mathias Meyer $^{3}$. \\ Marcel J. W. Greuter ${ }^{1}$ - Thomas Henzler ${ }^{3}$ - Thomas G. Flohr ${ }^{4}$ • Matthijs Oudkerk ${ }^{2}$. \\ Rozemarijn Vliegenthart ${ }^{1,2}$
}

Received: 29 January 2016 /Revised: 6 July 2016 / Accepted: 6 July 2016 / Published online: 29 August 2016

(C) The Author(s) 2016. This article is published with open access at Springerlink.com

\begin{abstract}
Objectives To evaluate detectability and quantification of coronary calcifications for CT with a tin filter for spectral shaping.

Methods Phantom inserts with 100 small and 9 large calcifications, and a moving artificial artery with 3 calcifications (speed $0-30 \mathrm{~mm} / \mathrm{s}$ ) were placed in a thorax phantom simulating different patient sizes. The phantom was scanned in highpitch spiral mode at $100 \mathrm{kVp}$ with tin filter $(\mathrm{Sn} 100 \mathrm{kVp})$, and at a reference of $120 \mathrm{kVp}$, with electrocardiographic (ECG) gating. Detectability and quantification of calcifications were analyzed for standard (130 HU) and adapted thresholds.

Results Sn100 kVp yielded lower detectability of calcifications ( $9 \%$ versus $12 \%, p=0.027$ ) and lower Agatston scores $(p<0.008)$, irrespective of calcification, patient size and speed. Volume scores of the moving calcifications for Sn100 $\mathrm{kVp}$ at speed $10-30 \mathrm{~mm} / \mathrm{s}$ were lower $(p<0.001)$, while mass scores were similar $(p=0.131)$. For $\mathrm{Sn} 100 \mathrm{kVp}$ with adapted threshold of $117 \mathrm{HU}$, detectability $(p=1.000)$ and Agatston score $(p>0.206)$ were similar to $120 \mathrm{kVp}$. Spectral shaping
\end{abstract}

Rozemarijn Vliegenthart

r.vliegenthart@umcg.nl

1 Department of Radiology, University of Groningen, University Medical Center Groningen, Hanzeplein 1, EB44, 9713

GZ Groningen, The Netherlands

2 Center for Medical Imaging North-East Netherlands (CMI-NEN), University of Groningen, University Medical Center Groningen, Hanzeplein 1, Groningen, The Netherlands

3 Institute of Clinical Radiology and Nuclear Medicine, Medical Faculty Mannheim, University Medical Center Mannheim, Heidelberg University, Heidelberg, Germany

4 Siemens Healthcare GmbH, Computed Tomography, Forchheim, Germany resulted in median dose reduction of $62.3 \%$ (range 59.0$73.4 \%)$.

Conclusions Coronary calcium scanning with spectral shaping yields lower detectability of calcifications and lower Agatston scores compared to $120 \mathrm{kVp}$ scanning, for which a HU threshold correction should be developed.

Key points

- Sn100kVp yields lower detectability and lower Agatston scores compared to $120 \mathrm{kVp}$

- Adapted HU threshold for Sn100kVp provides Agatston scores comparable to $120 \mathrm{kVp}$

- Sn100 kVp considerably reduces dose in calcium scoring versus $120 \mathrm{kVp}$

Keywords Computed tomography $\cdot$ Coronary arteriosclerosis · Cardiovascular Diseases · Imaging · Mass screening

$\begin{array}{ll}\text { Abbreviations } \\ \text { CT } & \text { Computed tomography } \\ \text { ECG } & \text { Electrocardiographic } \\ \text { DSCT } & \text { Dual source computed tomography } \\ \text { HU } & \text { Hounsfield unit } \\ \text { Sn100 } & \text { Tube voltage of 100 kVp with tin spectral } \\ \text { kVp } & \text { shaping } \\ \text { FOV } & \text { Field -of -view } \\ \text { CTDIvol } & \text { Computed tomography dose index } \\ \text { DLP } & \text { Dose-length product } \\ \text { IQR } & \text { Interquartile range }\end{array}$

\section{Introduction}

Since the publication of the considerable lung cancer mortality reduction due to computed tomography (CT) screening in the 
National Lung Screening Trial [1], lung cancer screening has become recommended by US and European healthcare organizations [2-4]. The advent of low-dose CT lung cancer screening may also offer the opportunity to screen for coronary calcifications. It is well known that smoking, the main risk factor for lung cancer, is also a major risk factor for cardiovascular disease. Thus, screening for cardiovascular disease combined with early detection of lung cancer, may improve the cost-effectiveness of chest CT screening.

The dose of chest CT imaging in third generation dualsource CT (DSCT) can be further reduced by spectral shaping of the x-ray beam due to pre-filtration by a tin filter placed behind the $\mathrm{x}$-ray tube. The potential for radiation dose reduction in lung cancer screening with this ultra-low dose chest $\mathrm{CT}$ was recently shown $[5,6]$. A dose reduction up to $90 \%$ was achieved with spectral shaping and advanced iterative reconstruction, while maintaining a high sensitivity of pulmonary nodule detection [5].

The use of spectral shaping by a tin filter leads to a narrower x-ray tube spectrum with fewer quanta at low energies, which shifts the mean energy of the spectrum to higher values [5]. The higher mean photon energy results in lower Hounsfield Unit (HU) values of tissues, including coronary calcifications. The maximum HU -value of a calcification affects the calcium score because of the multi-threshold calculation in the Agatston scoring method [7]. Calcifications with a maximum value below a threshold of $130 \mathrm{HU}$ are not included in the Agatston score. It is unknown how the higher mean photon energy due to the tin filter influences the detectability of small coronary calcifications and the resulting calcium scores for various patient sizes and for moving coronary arteries. When changing the $\mathrm{CT}$ protocol for calcium scoring by spectral shaping, it is essential that the detectability of coronary calcification remains similarly high, and that the resulting calcium scores are comparable with original results in order not to affect cardiovascular risk stratification.

The purpose of this phantom study was to evaluate the detectability and quantification of coronary calcifications for a CT system with a tin filter for spectral shaping.

\section{Materials and methods}

\section{Phantom}

An anthropomorphic chest CT phantom (Thorax, QRM, Möhrendorf, Germany) with a cylindrical opening at the position of the heart was used to simulate a small patient size. Fat-equivalent extension rings (extension rings $\mathrm{M}$ and $\mathrm{L}$, QRM, Möhrendorf) were placed around the phantom to mimic medium and large patient size (see Fig. 1).

Three inserts with calcifications mimicking coronary calcium were consecutively placed into the cylindrical opening of
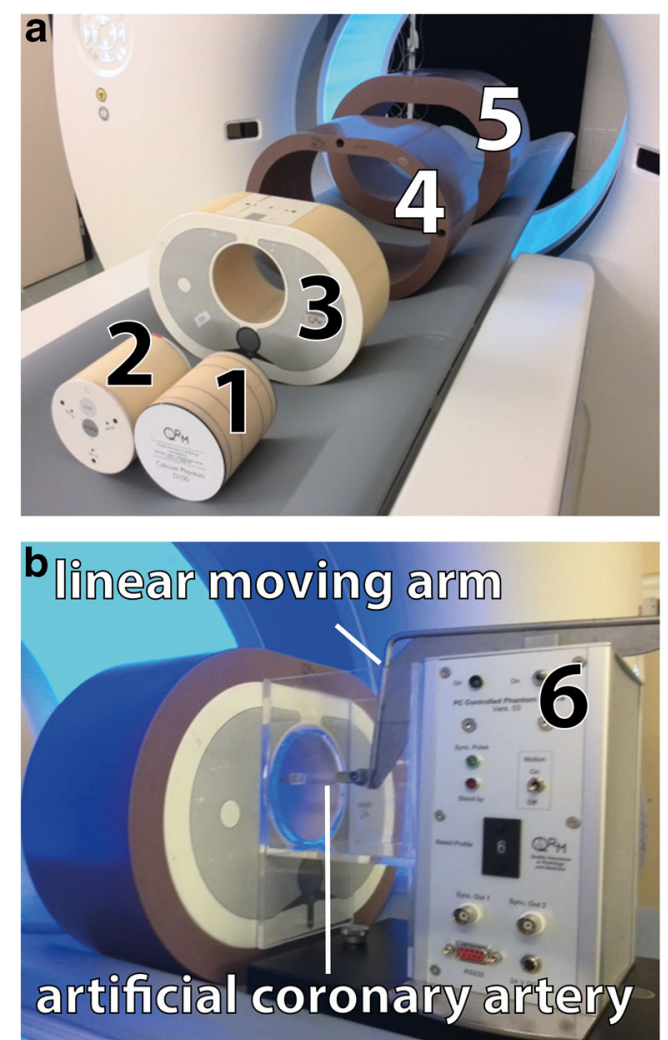

Fig. 1 The QRM cardiac phantom set-up with different calcium inserts. (a, b) The inserts $(1,2,6)$ were consecutively placed in the thorax phantom (3) and additional rings $(4,5)$ were used to simulate medium and large patient sizes. 1) D100 insert; 2) CCI insert; 3) Thorax phantom; 4) Phantom ring representing a medium patient size; 5) Phantom ring representing a large patient size; 6) Sim2D in which the artificial coronary artery with three calcifications is placed

the phantom. The first insert, D100, contained 100 small cylindrical calcifications (D100, QRM, Möhrendorf) varying in density $\left(90-540 \mathrm{mgHA} / \mathrm{cm}^{3}\right)$ and size $\left(0.1-6.3 \mathrm{~mm}^{3}\right)$ [8]. The D100 insert was used to determine the detectability of small calcifications. The second insert, CCI, contained 9 slightly larger cylindrical calcifications (CCI, QRM, Möhrendorf) with varying density $\left(200,400\right.$ and $\left.800 \mathrm{mgHA} / \mathrm{cm}^{3}\right)$ and size $\left(0.8,21.2\right.$ and $\left.98.2 \mathrm{~mm}^{3}\right)$ [9]. The CCI insert was used to determine the Agatston score, volume and mass for larger calcifications. The third insert consisted of a linear moving artificial coronary artery (Sim2D, QRM, Möhrendorf, Germany) with 3 calcified lesions, with density of 401 $\mathrm{mgHA} / \mathrm{cm}^{3}$ and varying size $\left(9.1,24.6\right.$ and $\left.62.8 \mathrm{~mm}^{3}\right)$ [10]. The coronary artery moved at a speed of $0,10,20$ and $30 \mathrm{~mm} /$ $\mathrm{s}$, corresponding to the expected velocity range of an in -vivo coronary artery during ECG- gated acquisitions [10, 11].

\section{Image acquisition}

The thorax phantom and calcium inserts were scanned with a third- generation DSCT scanner (Somatom Force, Siemens, Erlangen, Germany) in high-pitch spiral mode. As a reference, 
data sets were acquired at a tube voltage of $120 \mathrm{kVp}$ and tube current of 90 reference mAs. Next, data sets were acquired at a tube voltage of $100 \mathrm{kVp}$ with spectral shaping due to the 0.6$\mathrm{mm}$ tin filter $(\mathrm{Sn} 100 \mathrm{kVp})$ and tube current of 180 reference mAs. ECG gating was used for acquisitions of the moving coronary artery at $\mathrm{Sn} 100 \mathrm{kVp}$ and $120 \mathrm{kVp}$. The data were reconstructed with a field- of- view (FOV) of $250 \mathrm{~mm}$ and a $512 \times 512$ matrix, a sharp reconstruction filter (Qr36d) and filtered back projection at a slice thickness of $3.0 \mathrm{~mm}$ and an increment of $1.5 \mathrm{~mm}$ (to avoid over- or undersampling) [12]. Acquisitions were repeated four times for D100, five times for CCI and three times for Sim2D with a small translation and rotation between each acquisition.

\section{Image analysis}

Calcium detectability was determined automatically using a Matlab script [8]. Analysis of the CCI and Sim2D data were performed manually with Aquarius iNtuition Viewer (Version 4.1.11, TeraRecon Inc, Foster City, CA, USA). A calcification was defined as a region with a peak value of $\geq 130$ HU (standard calcium threshold) and comprising $\geq 2$ adjacent voxels (eight-connected connectivity [13]). The calcium detectability was defined as the total number of detected calcifications in the D100 insert. In general, the less sensitive an acquisition is for small and low- density calcifications, the lower the number of detected calcifications [8]. For Sn100 kVp and $120 \mathrm{kVp}$, the standard calcium threshold for Agatston score, volume and mass was used, and median and interquartile ranges (IQRs) of the repetitions were calculated, and coefficient of variation for all scores were calculated [9].

In addition, optimization of detectability and calcium scores was performed by adapting the calcium threshold for Sn100 $\mathrm{kVp}$. The mean HU of the four calibration planes in the D100 insert for both protocols was determined (including all repetitions and patient sizes) and the threshold for $\mathrm{Sn} 100 \mathrm{kVp}\left(\mathrm{t}_{\mathrm{Sn} 100}\right.$ $\mathrm{kVp}$ ) scans was calculated, using the following formula [14]:

$t_{S n 100 k V p}=130 H U\left(\frac{\text { mean } H U_{c a H A @ S n 100 k V p}}{\text { mean } H U_{c a H A @ S n 120 k V p}}\right)$

\section{Radiation dose}

The radiation dose parameters, computed tomography dose index $\left(\mathrm{CTDI}_{\mathrm{vol}}\right)$ and dose-length product (DLP), were taken from the electronically logged protocol from each CT study.

\section{Statistical analysis}

Kruskal-Wallis testing was used to analyze differences in detectability of calcifications, Agatston score, volume score and mass scores between $\mathrm{Sn} 100 \mathrm{kVp}$ and $120 \mathrm{kVp}$ acquisitions.
The Kruskal-Wallis test was performed separately for each patient size. If the Kruskal-Wallis test showed a significant difference in distribution of outcomes, one-by-one comparison was performed by using the Mann-Whitney U test, again for each patient size separately. Kendall's tau-b was used to analyze trends in Agatston, volume and mass score based on speed (SPSS Statistics, version 22, IBM, USA). $P<0.05$ was considered to indicate a statistically significant difference.

\section{Results}

\section{Calcium detectability at standard calcium threshold}

The overall median detectability was 9.0 (IQR: 8.0-9.9) out of 100 calcifications at $\mathrm{Sn} 100 \mathrm{kVp}$, and 12.0 (IQR: 11.0-13.0) at $120 \mathrm{kVp}$ (see Table 1). The overall median calcium detectability was $25 \%$ lower at $\mathrm{Sn} 100 \mathrm{kVp}$ compared to the detectability at $120 \mathrm{kVp}(p=0.027)$.

\section{Quantification of calcifications at standard calcium threshold}

Coefficient of variation for all patient sizes at $\mathrm{Sn} 100 \mathrm{kVp}$ (CCI) was of comparable magnitude for the mass score $(2.6 \%)$ and Agatston score $(2.7 \%)$ and largest for the volume score $(4.7 \%)$.

\section{Agatston score}

The overall median Agatston score at $\mathrm{Sn} 100 \mathrm{kVp}$ was 600.8 (IQR: 593.7-621.3) and 638.3 (IQR: 625.7-653.2) at $120 \mathrm{kVp}$ for the CCI insert. The Agatston score was significantly lower at $\operatorname{Sn} 100 \mathrm{kVp}(p=0.008)$ for each patient size, except for the CCI insert for large size $(p=0.548$; see Fig. 2a).

The Agatston score decreased significantly with increasing speed for $\operatorname{Sn} 100 \mathrm{kVp}\left(\tau_{\mathrm{b}}=-0.383, p=0.003\right)$ and for $120 \mathrm{kVp}\left(\tau_{\mathrm{b}}=-0.442, p=0.001\right)$. The median Agatston score was 113.6 (IQR: 98.9-129.6) at Sn100 $\mathrm{kVp}$ and 149.0 (IQR: $130.0-160.0$ ) at $120 \mathrm{kVp}$. The Agatston score was lower at $\mathrm{Sn} 100 \mathrm{kVp}$ compared to $120 \mathrm{kVp}$ for the moving artificial coronary artery (speeds 0-30 mm/s; $p<0.001$; see Fig. 3a).

2. Volume score

The median overall volume score of the CCI insert was 603.9 (IQR: $593.8-618.7$ ) $\mathrm{mm}^{3}$ at $\mathrm{Sn} 100 \mathrm{kVp}$, and was 610.0 (IQR: $598.1-626.6) \mathrm{mm}^{3}$ at $120 \mathrm{kVp}$, while the physical volume was $360.6 \mathrm{~mm}^{3}$. No significant difference in total volume score was found between $\mathrm{Sn} 100 \mathrm{kVp}$ and $120 \mathrm{kVp}(p<0.206)$ for the CCI insert (see Fig. 2b).

The total physical volume of the calcifications in the artificial coronary artery of the Sim2D insert was $96.5 \mathrm{~mm}^{3}$. The median volume score was 127.9 (IQR: 
Table 1 Calcium detectability of small calcifications out of a total of 100 calcifications for small, medium, and large patient size at standard calcium threshold

\begin{tabular}{llll}
\hline & \multicolumn{2}{l}{ Scan protocol } & \\
\cline { 2 - 3 } Patient size & $\begin{array}{l}\text { Sn100 kVp } \\
\text { Median (IQR) } \\
\mathrm{n}=*\end{array}$ & $\begin{array}{l}120 \mathrm{kVp} \\
\text { Median (IQR) } \\
\mathrm{n}=*\end{array}$ & $\begin{array}{l}\text { Percentage difference } \\
\text { of medians }\end{array}$ \\
\hline Small & $9.0(9.0-11.3)$ & $12.5(12.0-13.0)$ & $28 \%$ \\
Medium & $8.5(6.5-10.5)$ & $11.0(11.0-12.5)$ & $23 \%$ \\
Large & $8.8(6.5-9.9)$ & $11.5(11.0-12.8)$ & $25 \%$ \\
All sizes & $9.0(8.0-9.9)$ & $12.0(11.0-13.0)$ & $25 \%$ \\
\hline
\end{tabular}

* Median number of absolute detected calcifications in four consecutive measurements

$116.0-143.1) \mathrm{mm}^{3}$ at $\mathrm{Sn} 100 \mathrm{kVp}$ and 147.0 (IQR: 138.0 $157.0) \mathrm{mm}^{3}$ at $120 \mathrm{kVp}(0-30 \mathrm{~mm} / \mathrm{s})$. No difference in volume score was found between $\mathrm{Sn} 100 \mathrm{kVp}$ and 120
$\mathrm{kVp}$ for measurements with no movement of the coronary artery (speed $0 \mathrm{~mm} / \mathrm{s} ; p=0.347$ ). However, the volume score was significantly lower at $\mathrm{Sn} 100 \mathrm{kVp}$ compared to
Fig. 2 Calcium scores of three patient sizes at $\mathrm{Sn} 100 \mathrm{kVp}$ and $120 \mathrm{kVp}$ of the CCI insert, at standard calcium threshold (130 HU). The median and interquartile ranges for: (a) Agatston score, (b) Volume, (c) Mass
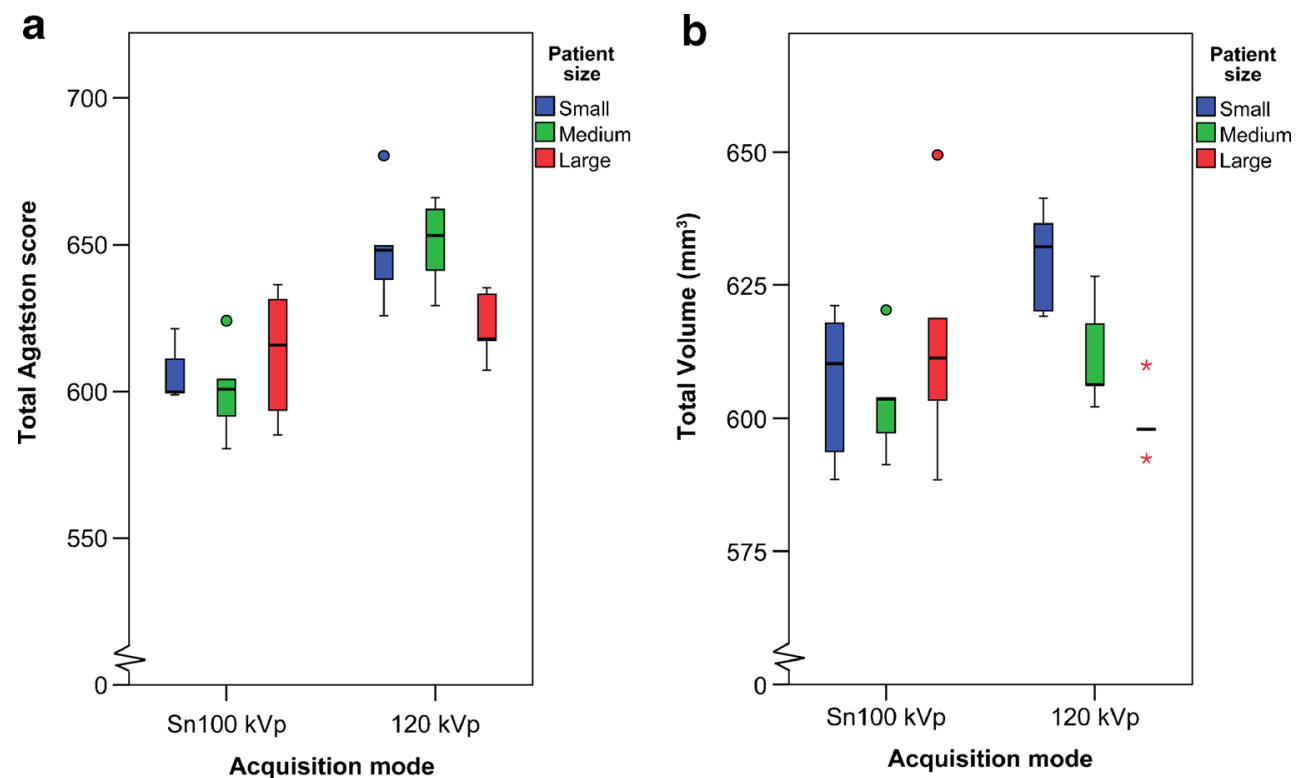

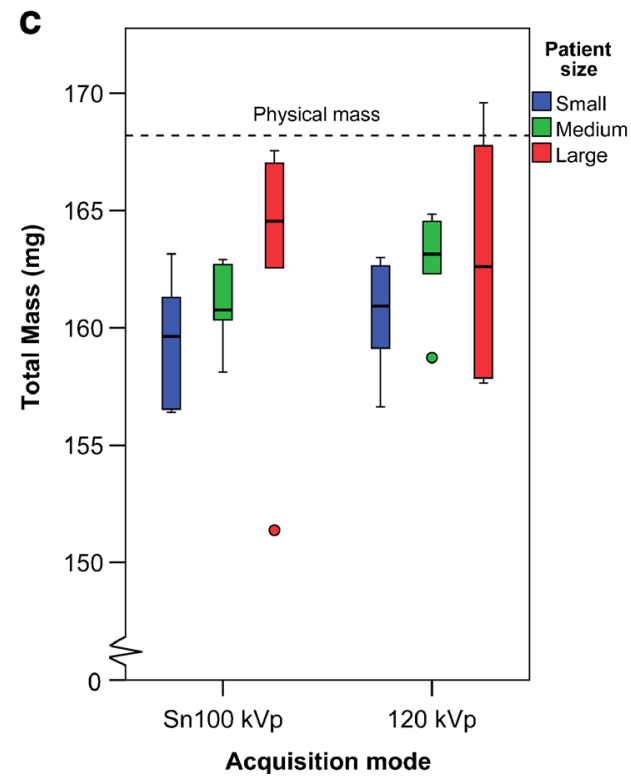


Fig. 3 Calcium scores of the artificial coronary artery moving at speeds of $0-30 \mathrm{~mm} / \mathrm{s}$ at $\mathrm{Sn} 100$ $\mathrm{kVp}$ and $120 \mathrm{kVp}$ for electrocardiographically (ECG)gated acquisitions, at standard calcium threshold (130 HU). The median and interquartile ranges for: (a) Agatston score, (b) Volume, (c) Mass
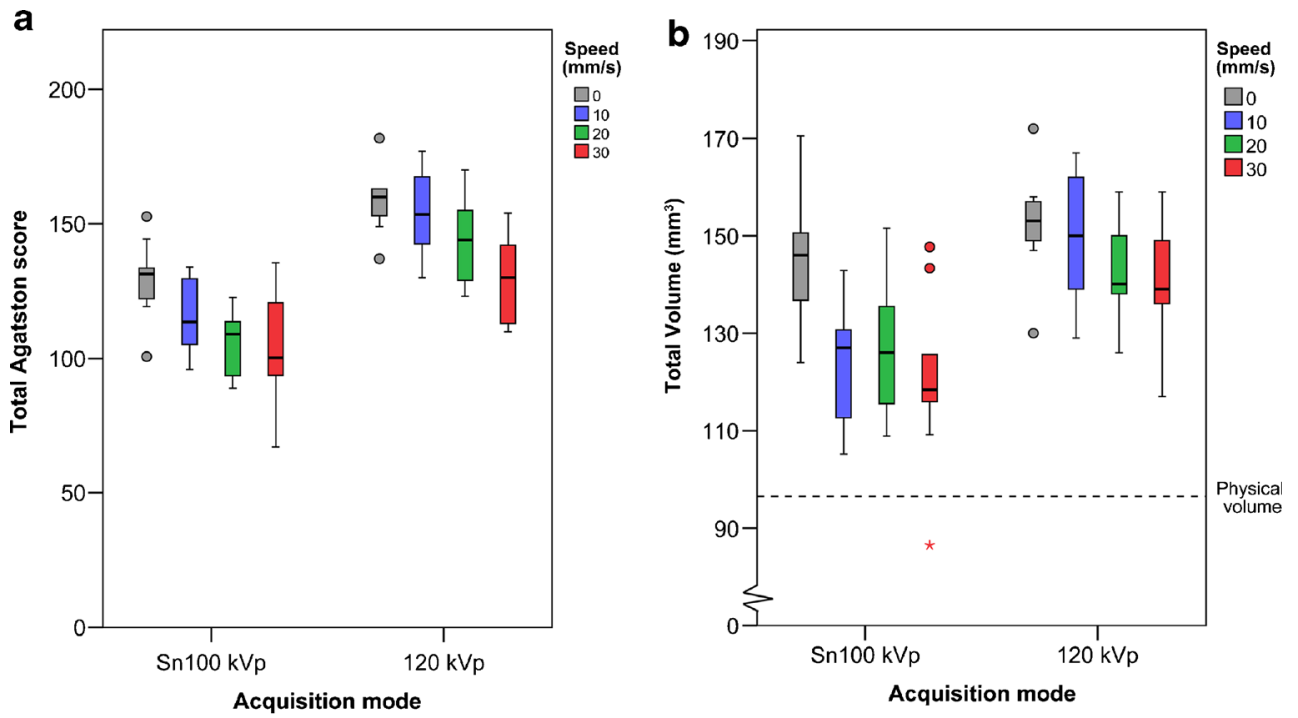

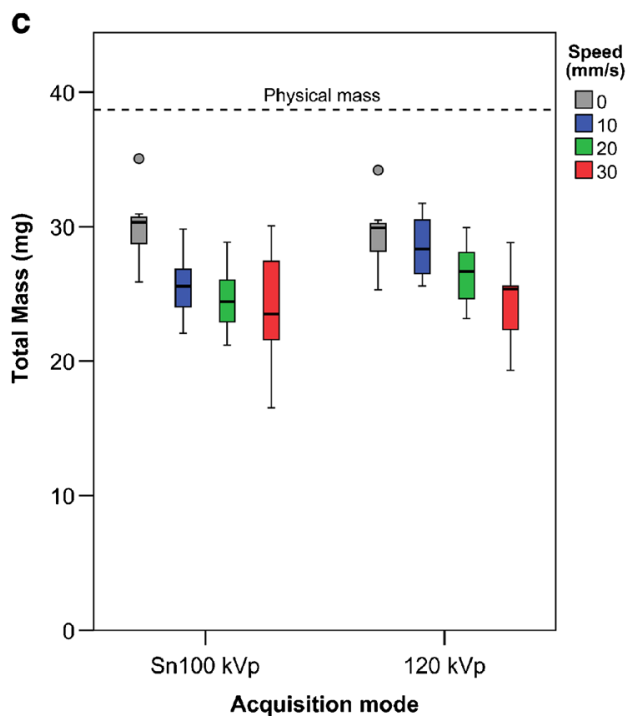

$120 \mathrm{kVp}$ taken all the measurements with the coronary artery moving at $10-30 \mathrm{~mm} / \mathrm{s}$ together $(p<0.001)$. The volume score decreased significantly with increasing speed for $\operatorname{Sn} 100 \mathrm{kVp}\left(\tau_{\mathrm{b}}=-0.325, p<0.011\right)$ as well as for 120 $\mathrm{kVp}\left(\tau_{\mathrm{b}}=-0.303, p=0.021\right.$; see Fig. $\left.3 b\right)$.

3. Mass score

The median overall mass score of the CCI insert at Sn100 kVp was 161.3 (IQR: 158.1-163.2) mg, and 162.6 (IQR: $158.7-164.5) \mathrm{mg}$ at $120 \mathrm{kVp}$, while the physical mass was $168.2 \mathrm{mg}$. No significant difference in mass score was found between $\mathrm{Sn} 100 \mathrm{kVp}$ and $120 \mathrm{kVp}$ $(p<1.00)$ for the CCI insert (see Fig. 2c).

The physical mass of the calcifications in the artificial coronary artery of the Sim2D insert was $38.7 \mathrm{mg}$. The median mass score at $\mathrm{Sn} 100 \mathrm{kVp}$ was 25.9 (IQR: 23.029.1) $\mathrm{mg}$ and 27.1 (IQR: 25.4-29.7) $\mathrm{mg}$ at $120 \mathrm{kVp}$. The mass score decreased significantly with increasing speed for $\mathrm{Sn} 100 \mathrm{kVp}\left(\tau_{\mathrm{b}}=-0.459, p<0.001\right)$ as well as for 120
$\mathrm{kVp}\left(\tau_{\mathrm{b}}=-0.507, p<0.001\right.$; see Fig. $\left.3 \mathrm{c}\right)$. No significant difference in mass score was found for Sn100 kVp and $120 \mathrm{kVp}$ for measurements with no (speed $0 \mathrm{~mm} / \mathrm{s}$, $p=0.347)$ or minor movement $(10-30 \mathrm{~mm} / \mathrm{s}, p=0.131)$ of the coronary artery.

\section{Optimization of detectability and calcium scores for Sn100 kVp}

The adapted calcium threshold for Sn100 kVp was $117 \mathrm{HU}$. The overall median detectability at $\mathrm{Sn} 100 \mathrm{kVp}$ with calcium threshold of $117 \mathrm{HU}$ was 11.5 (IQR: 10.0-12.8) out of 100 calcifications, and no significant difference in detectability was found compared to $120 \mathrm{kVp}(p=1.000)$.

The overall median Agatston score of the CCI insert was 657.4 (IQR: 651.1-675.2). No significant difference in median Agatston score was found at Sn100 kVp with $117 \mathrm{HU}$ threshold 
compared to $120 \mathrm{kVp}$ for small and medium patient size $(p>0.206)$. However, at Sn100 kVp and $117 \mathrm{HU}$ the volume $(p<0.008)$ and mass $(p<0.008)$ score of the CCI insert were significantly higher for small and medium patient size compared to $120 \mathrm{kVp}$.

\section{Radiation dose}

The mean $\mathrm{CTDI}_{\mathrm{vol}}$ for small to large patient size was 0.16$0.65 \mathrm{mGy}$ at Sn $100 \mathrm{kVp}$ and $0.44-2.44 \mathrm{mGy}$ at $120 \mathrm{kVp}$. The mean DLP was $1.6-6.5 \mathrm{mGy} \cdot \mathrm{cm}$ and $4.3-24.4 \mathrm{mGy} \cdot \mathrm{cm}$ for $\mathrm{Sn} 100 \mathrm{kVp}$ and $120 \mathrm{kVp}$, respectively.

\section{Discussion}

This phantom study evaluated the detectability and quantification of coronary calcifications using third- generation DSCT with spectral shaping, by comparing a Sn $100 \mathrm{kVp}$ protocol with the reference $120 \mathrm{kVp}$ scan protocol. We found that the $\mathrm{Sn} 100 \mathrm{kVp}$ scan protocol with standard HU threshold, resulted in lower detectability of calcifications and lower calcium scores regardless of coronary movement. Adaptation of the HU threshold for calcium scoring at $\mathrm{Sn} 100 \mathrm{kVp}$ resulted in similar detectability and Agatston score for small and medium patient size. Besides, the $\mathrm{Sn} 100 \mathrm{kVp}$ protocol led to a major decrease in radiation dose of $63 \%$ to $73 \%$ for, respectively, small to large patient size.

Until now, the use of spectral shaping in CT scanning has only been examined for non-contrast enhanced chest CT $[5,6]$ and recently in one cardiac CT study by McQuiston et al. in a simplified setting [15]. In this study, we comprehensively describe the impact of a tin filter in coronary calcification scanning. The $120-\mathrm{kVp}$ protocol at third- generation DSCT showed calcium score results similar to those obtained on previous CT systems [9, 16, 17]. For example, the mean Agatston score of the CCI insert at $120 \mathrm{kVp}$ was 640.4 , which falls within the range of the Agatston score of 605.0-655.4 based on different MDCTs in the study of McCollough et al. [9]. The Agatston score for the CCI insert was slightly lower for the $\mathrm{Sn} 100 \mathrm{kVp}$ protocol compared to the scores determined with general coronary calcium protocols on various CT systems $[9,16,17]$. For example, the mean Agatston score for $\mathrm{Sn} 100 \mathrm{kVp}$ was 606.3 , which is at the lower limit of the range reported by McCollough et al. [9]. The study by McQuistion et al. recently showed no significant difference in Agatston score between $\mathrm{Sn} 100 \mathrm{kVp}$ and 120 $\mathrm{kVp}$ for the CCI insert for small patient size using standard HU threshold [15], while our study did show a difference in Agatston score for small patient size. Possibly, the use of various tube currents and lack of scan repetition in the study of McQuistion et al. explains this difference. Furthermore, the studies of Ulzheimer et al. and Groen et al. showed that calcium scores decrease with increasing heart rate, which is in accordance with our results for increasing speed of the moving artificial coronary artery for $120 \mathrm{kVp}$ as well as for $\mathrm{Sn} 100 \mathrm{kVp}[18,19]$. Based on these findings, we assume that the $120-\mathrm{kVp}$ protocol on third- generation DSCT leads to results similar to those from coronary calcium scan protocols on other CT- systems, while the $\mathrm{Sn} 100 \mathrm{kVp}$ protocol leads to lower calcium scores compared to the protocols on other CT- systems. On the contrary, McQuiston et al. suggested that use of a tin filter does not impact the calcium score [15]. However, in their study, small calcifications (sub-millimeter), different patient sizes, coronary artery movement, calcium mass and inter-scan variability were not included, while all these variables by themselves are important factors to consider in calcium scoring.

The results of our study imply that the use of the Sn100-kVp protocol for coronary calcium scanning could have two major consequences in determining the appropriate cardiovascular risk in clinical practice. Firstly, the lower calcification detectability of the Sn100- $\mathrm{kVp}$ protocol at standard threshold of $130 \mathrm{HU}$ could lead to underestimation and false-negative calcium scores in patients. This would result in addressing a patient's cardiovascular risk inappropriately as 'very low'. Secondly, the use of spectral shaping led to lower Agatston scores, which may result in reclassification of the patient into a lower cardiovascular risk category. Hence, a lower Agatston score or false-negative score could lead to an underestimation of the cardiovascular risk. In this study we tried to compensate for this underestimation of $S n 100 \mathrm{kVp}$ by lowering the calcium threshold for $\mathrm{Sn} 100 \mathrm{kVp}$ from $130 \mathrm{HU}$ to $117 \mathrm{HU}$. This improved the detectability and Agatston score for Sn100 kVp, such that there was no longer a significant difference with conventional $120 \mathrm{kVp}$. However, the volume and mass score were higher at $\mathrm{Sn} 100 \mathrm{kVp}$ compared to $120 \mathrm{kVp}$, but these scores, although more reproducible, are not used in clinical practice.

The large reduction in radiation dose with the $\mathrm{Sn} 100-\mathrm{kVp}$ protocol is a large advantage over the conventional $120-\mathrm{kVp}$ protocol. This is of special interest when screening of coronary calcium is combined with lung cancer screening or in the case that population screening for coronary calcium is introduced in clinical practice. This study does not provide answers with regard to possible reclassification of screenees if a $\mathrm{Sn} 100-\mathrm{kVp}$ protocol is used. This should be investigated in future studies. Besides, a recent study showed that ungated chest $\mathrm{CT}$ acquisitions might be used for CAC risk stratification [20], simplifying a combined coronary calcium and lung screening acquisition.

This study has some limitations. First, the tube current was modulated for each patient size. However, for the large patient size at $\mathrm{Sn} 100 \mathrm{kVp}$, the tube current could not be further increased beyond a quality reference of $180 \mathrm{mAs}$, in case of the high-pitch spiral mode. This resulted in a higher noise 
level for the larger patient sizes at the $\mathrm{Sn} 100-\mathrm{kVp}$ protocol compared to the $120-\mathrm{kVp}$ protocol. However, former studies have shown minor influence of tube current or noise level on coronary calcium scoring [21, 22].

A second, general, limitation is that cardiovascular risk stratification can only be performed based on the Agatston score, because of its well-known prognostic value [7, 23-28]. As an alternative to the Agatston score, several studies recommend determining the total mass of all calcifications because of its higher inter- and intra-scanner reproducibility $[9,29,30]$. Also, our study showed that the mass score is the most consistent score across patient sizes for the $\mathrm{Sn} 100-\mathrm{kVp}$ protocol. At the standard calcium threshold of $130 \mathrm{HU}$, in contrast to the Agatston score, no significant difference in mass score was found between $\mathrm{Sn} 100 \mathrm{kVp}$ and $120 \mathrm{kVp}$ for any patient size for the moving coronary artery. However, with the adapted HU threshold for calcium scoring, we also found similar detectability and Agatston scores.

In conclusion, this phantom study showed that spectral shaping in coronary calcium scanning reduces the radiation dose but leads to a lower detection of calcifications and lower Agatston scores, which could result in underestimation of the cardiovascular risk in patients. In the future, underestimation may be corrected by adapting the HU threshold for calcium scoring using a scan protocol with spectral shaping.

Acknowledgments The scientific guarantor of this publication is Dr. R. Vliegenthart. The authors of this manuscript declare relationships with the following companies: Thomas Henzler and Mathias Meyer: Institutional research funding from Siemens within the context of the Research Campus $\mathrm{M}^{2} \mathrm{OLIE}$ funded by the German Federal Ministry of Education and Research (BMBF) within the Framework "Forschungscampus: public-private partnership for Innovations" under the funding code 13GW00926. Thomas Flohr: Employee of Siemens Healthcare GmbH, Forchheim, Germany. This co-author was not involved in performing the experiments nor had any influence on statistics or results. Rozemarijn Vliegenthart is supported by a grant from the Netherlands Organisation for Scientific Research. All other authors of this manuscript declare no relationships with any companies, whose products or services may be related to the subject matter of the article. The authors state that this work has not received any funding. No complex statistical methods were necessary for this paper. Institutional review board approval was not required because this was an experimental (phantom) study. Methodology: prospective, experimental, performed at one institution.

Open Access This article is distributed under the terms of the Creative Commons Attribution 4.0 International License (http:// creativecommons.org/licenses/by/4.0/), which permits unrestricted use, distribution, and reproduction in any medium, provided you give appropriate credit to the original author(s) and the source, provide a link to the Creative Commons license, and indicate if changes were made.

\section{References}

1. The National Lung Screening Trial Research Team (2015) Reduced Lung-Cancer Mortality with Low-Dose Computed Tomographic Screening. N Engl J Med 365:395-409
2. Wender R, Fontham ETH, Barrera E et al (2013) American Cancer Society Lung Cancer Screening Guidelines Richard. CA Cancer J Clin 63:107-117

3. Jaklitsch MT, Jacobson FL, Austin JHM et al (2012) The American Association for Thoracic Surgery guidelines for lung cancer screening using low-dose computed tomography scans for lung cancer survivors and other high-risk groups. J Thorac Cardiovasc Surg 144:33-38

4. Kauczor H-U, Bonomo L, Gaga M et al (2015) ESR/ERS white paper on lung cancer screening. Eur Radiol 25:2519-2531

5. Gordic S, Morsbach F, Schmidt B et al (2014) Ultralow-Dose Chest Computed Tomography for Pulmonary Nodule Detection. Investig Radiol 49:465-473

6. Newell JD, Fuld MK, Allmendinger T et al (2015) Very Low-Dose ( $0.15 \mathrm{mGy}$ ) Chest CT Protocols Using the COPDGene 2 Test Object and a Third-Generation Dual-Source CT Scanner With Corresponding Third-Generation Iterative Reconstruction Software. Investig Radiol 00:1-6

7. Agatston AS, Janowitz FWR, Hildner FJ et al (1990) Quantification of Coronary Artery Calcium Using Ultrafast Computed Tomography. JACC 15:827-832

8. Groen JM, Kofoed KF, Zacho M et al (2013) Calcium score of small coronary calcifications on multidetector computed tomography: Results from a static phantom study. Eur J Radiol 82:e58-e63

9. McCollough CH, Ulzheimer S, Halliburton SS et al (2007) Coronary Artery Calcium: A Multi-institutional, Multimanufacturer International Standard for Quantification at Cardiac CT. Radiology 243:527-538

10. Xie X, Greuter MJW, Groen JM et al (2013) Can nontriggered thoracic CT be used for coronary artery calcium scoring? A phantom study. Med Phys 40:081915,1-10

11. Husmann L, Leschka S, Frauenfelder T et al (2007) Coronary Artery Motion and Cardiac Phases: Dependency on Heart Rate Implication for CT Image Reconstruction. Radiology 245:567-576

12. Weininger M, Ritz KS, Schoepf UJ et al (2012) Interplatform Reproducibility of CT Coronary Calcium Scoring Software. Radiology 265:70-77

13. van Ooijen PMA, Vliegenthart R, Witteman JC, Oudkerk M (2005) Influence of scoring parameter settings on Agatston and volume scores for coronary calcification. Eur Radiol 15:102-110

14. Thomas CK, Mühlenbruch G, Wildberger JE et al (2006) Coronary artery calcium scoring with multislice computed tomography: in vitro assessment of a low tube voltage protocol. Investig Radiol 41:668-673

15. McQuiston AD, Muscogiuri G, Schoepf UJ et al (2016) Approaches to ultra-low radiation dose coronary artery calcium scoring based on 3rd generation dual-source CT: A phantom study. Eur J Radiol 85:39-47

16. Deprez FC, Vlassenbroek A, Raaijmakers R, Coche E (2013) Controversies about effects of low-kilovoltage MDCT acquisition on Agatston calcium scoring. J Cardiovasc Comput Tomogr 7:58-61

17. Fujioka C, Funama Y, Kiguchi M et al (2012) Coronary Artery Calcium Scoring on Different 64-detector Scanners Using a Lowtub Voltage $(80 \mathrm{kVp})$. Acad Radiol 19:1402-1407

18. Ulzheimer S, Kalender WA (2003) Assessment of calcium scoring performance in cardiac computed tomography. Eur Radiol 13:484497

19. Groen JM, Greuter MJW, Vliegenthart R et al (2008) Calcium scoring using 64-slice MDCT, dual source CT and EBT: a comparative phantom study. Int J Cardiovasc Imaging 24:547-556

20. Hutt A, Duhamel A, Deken Vet al (2016) Coronary calcium screening with dual-source CT: reliability of ungated, high-pitch chest CT in comparison with dedicated calcium-scoring CT. Eur Radiol 26: $1521-1528$

21. Shemesh J, Evron R, Koren-Morag N et al (2005) Coronary artery calcium measurement with multi-detector row $\mathrm{CT}$ and low radiation dose: comparison between 55 and 165 mAs. Radiology 236:810-814 
22. Takahashi N, Bae KT (2003) Quantification of coronary artery calcium with multi-detector row $\mathrm{CT}$ : assessing interscan variability with different tube currents pilot study. Radiology 228:101-106

23. Rumberger JA, Simons DB, Fitzpatrick LA et al (1995) Coronary Artery Calcium Area by Electron-Beam Computed Tomography and Coronary Atherosclerotic Plaque Area - A Histopathologic Correlative Study. Circulation 92:2157-2162

24. Becker CR, Knez A, Jakobs TF et al (1999) Detection and quantification of coronary artery calcification with electron-beam and conventional CT. Eur Radiol 624:620-624

25. Hoff JA, Chomka EV, Krainik AJ et al (2001) Age and Gender Distributions of Coronary Artery Calcium Detected by Electron Beam Tomography in 35,246 Adults. Am J Cardiol 87:1335-1339

26. McClelland RL, Chung H, Detrano R et al (2006) Distribution of Coronary Artery Calcium by Race, Gender, and Age: Results from the Multi-Ethnic Study of Atherosclerosis (MESA). Circulation 113:30-37

27. Hoff JA, Daviglus ML, Chomka EVAV et al (2003) Conventional Coronary Artery Disease Risk Factors and Coronary Artery Calcium Detected by Electron Beam Tomography in 30,908 Healthy Individuals. Ann Epidemiol 13:163-169

28. Nucifora G, Bax JJ, Van Werkhoven JM et al (2011) Coronary artery calcium scoring in cardiovascular risk assessment. Cardiovasc Ther 29:43-53

29. Detrano R, Tang W, Kang X et al (1995) Accurate coronary calcium phosphate mass measurements from electron beam computed tomograms. Am J Card Imaging 9:167-173

30. Dijkstra H, Greuter MJW, Groen JM et al (2010) Coronary calcium mass scores measured by identical 64-slice MDCT scanners are comparable: a cardiac phantom study. Int J Cardiovasc Imaging 26:89-98 